\title{
Estimativa do desempenho reprodutivo na estação de monta com base em prévia avaliação da atividade ovariana por palpação retal
}

\section{Estimative of reproductive performance during breeding season based on previous ovarian activity evaluation by rectal palpation}

\author{
João H. M. Viana, ${ }^{*}$ Betina Winkler, ${ }^{\star \star}$ Ademir de Moraes Ferreira, ${ }^{\star \star *}$ Wanderley Ferreira de Sá ${ }^{\star \star \star}$
}

\begin{abstract}
Resumo
Objetivou-se avaliar o uso dos resultados de exame ginecológico por palpação retal na estimativa do desempenho reprodutivo de um rebanho, o que pode ser de grande auxílio no manejo de uma estação de monta. Foram utilizadas vacas e novilhas guzerá e mestiças guzerá x chianina, com condição corporal e período pós-parto variados. Os animais foram submetidos a exame ginecológico por palpação retal, duas semanas antes do início da estação de monta, e classificados em três grupos: anestro, sinais de atividade ovariana (AO) e atividade luteal cíclica (ALC). O número de animais apresentando cio durante os primeiros 45 dias da estação de monta foi menor $(p<0,001)$ no grupo classificado em anestro. Não houve diferença $(p>0,05)$ no número de animais em cio entre aqueles classificados em AO ou ALC. Não houve efeito da raça no número de animais em cio entre as classes predeterminadas. A elevada percentagem de animais sem cio, observada no grupo de vacas consideradas em anestro, refletiu-se em menor taxa de gestação em relação aos demais grupos. A caracterização da atividade luteal cíclica ovariana pela palpação retal, mesmo considerando-se a possível margem de erro da técnica, pode ser utilizada na estimativa do desempenho reprodutivo de um rebanho em estação de monta.
\end{abstract}

Palavras-chave: bovino; palpação retal; estação de monta.

\section{Introduçã̇o}

A utilização de períodos limitados do ano para a reprodução em bovinos (estações de monta) é uma prática bastante utilizada na pecuária de corte e, em menor escala, na pecuária leiteira, que apresenta vários benefícios econômicos e de manejo para o rebanho (Fonseca, 1991). Os resultados zootécnicos e econômicos obtidos em rebanhos submetidos à estação de monta dependem, diretamente, da eficiência reprodutiva dos mesmos. Diversos fatores estão envolvidos na fertilidade de um rebanho, como idade, genética, época do ano, manejo, condição sanitária, período pós-parto, estado nutricional, amamentação, etc., sendo os dois últimos de especial importância na pecuária de corte (Ferreira, 1990; Short et al., 1990; Fonseca, 1991). Ainda que o efeito de cada um destes fatores sobre a reprodução seja conhecido, grandes variações podem ser observadas entre indivíduos de um mesmo rebanho, o que, aliado à possibilidade de interação entre eles, pode comprometer as estimativas de performance reprodutiva do rebanho durante a estação de monta.

A palpação retal tem sido largamente usada na avaliação da atividade luteal cíclica em bovinos, e sua comparação com resultados de dosagens hormonais ou de ultrasonografia mostra uma margem de erro variável (Dawson, 1975; Ott et al., 1986; Sprecher et al., 1989; Hussein et al., 1992), sendo o diagnóstico normalmente realizado após exames subseqüentes. O acompanhamento periódico da atividade luteal cíclica em rebanhos de corte é difícil e oneroso, em razão de os rebanhos estarem sempre em locais distantes e constituídos por um grande número de animais

Objetivou-se com o presente trabalho verificar a validade de se utilizar a avaliação da atividade luteal cíclica, obtida com um único exame ginecológico por palpação retal realizado antes da estação de monta, como estimativa do desempenho reprodutivo nessa estação de monta.

\section{Material e métodos}

O trabalho foi conduzido em fazenda de gado de corte localizada no Município de Cantagalo, RJ. O rebanho utilizado era composto de vacas e novilhas guzerá e mestiças guzerá x chianina. As vacas apresentavam período pósparto e condição corporal variados. Utilizaram-se novilhas com peso superior a $300 \mathrm{~kg}$ (guzerá) ou $350 \mathrm{~kg}$ (mestiças).

\footnotetext{
* Escola de Veterinária, Universidade Federal de Minas Gerais, Belo Horizonte, MG, 31161-970 (e-mail jhmviana@ golg.com.br).

** Médico Veterinário Autônomo.

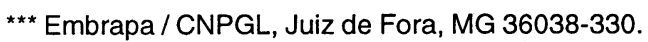


Duas semanas antes do início da estação de monta (04/ 01/93), todos os animais foram examinados, por palpação retal, para a identificação de anormalidades clínicas no trato genital e avaliação dos ovários, sendo classificados em três grupos, com base no resultado dos exames:

1. Anestro: ovários pequenos, duros e lisos, sem evidência palpável de crescimento folicular ou atividade luteal cíclica;

2. Sinais de atividade ovariana $(A O)$ : ovários de tamanho médio, com presença de folículos de tamanho variado, porém sem corpo lúteo palpável;

3. Atividade luteal cíclica (ALC): características semeIhantes às do grupo 2, porém com corpo lúteo palpável em um dos ovários, sugerindo atividade luteal cíclica. Foram incluídos neste grupo os animais sem corpo lúteo, mas com características de cio no dia do exame (presença de folículo de diâmetro pré-ovulatório, útero túrgido, descarga vaginal de muco, sinais psíquicos de cio).

Os animais foram distribuídos em lotes, em função do manejo normal da fazenda, e mantidos em piquetes constituídos basicamente de brachiaria decumbens e brizanta. A estação de monta foi programada para 90 dias, com os primeiros 45 dias destinados à inseminação artificial, e os 45 dias restantes ao repasse com reprodutores, de raça diferente dos utilizados na I.A. A identificação de cio foi realizada às 6 horas e às 18 horas, por um período mínimo de 30 minutos, por pessoal devidamente treinado, com auxílio de rufiões, constituídos de fêmeas androgenizadas com buçal marcador. Os animais em cio foram inseminados após. 12 horas, utilizando-se diferentes sêmens em função do lote e/ou categoria de cada animal. Não houve observação sistemática de cio durante o período de repasse com touros. O diagnóstico de gestação foi realizado 50 dias após o término da estação de monta.

\section{Análise estatística}

O número de animais em cio durante os primeiros 45 dias, sem cio observado e prenhes ao final da estação, foi registrado em função dos grupos classificados anteriormente pelas características ovarianas. As diferenças no número de animais manifestando cio em função do período da estação, do grupo e da raça foram analisadas pelo método do Qui-quadrado (Gomes, 1985).

\section{Resultados e discussão}

Avaliaram-se 273 animais, dos quais 11 (4,03\%) foram descartados da estação de monta pelos seguintes motivos: prenhez $(n=3)$, problemas reprodutivos $(n=4)$ e zootécnicos diversos $(n=4)$, como idade, tetos perdidos e temperamento agressivo. Outros 55 animais não foram utilizados na análise estatística, por terem sido submetidos a manejo reprodutivo diferente. Os resultados de 207 avaliações encontram-se na Tabela 1. Do total examinado, 97 animais $(46,86 \%)$ foram classificados como em anestro, $81(39,13 \%)$ como apresentando atividade luteal cíclica, e $29(14,01 \%)$ como tendo sinais de atividade ovariana. 0 grande número de animais diagnosticado em anestro $(46,86$ $\%)$ pode estar relacionado à condição corporal inferior e ao período do parto no início da estação, conforme citados por Ferreira (1990) e Fonseca (1991). Dos animais avaliados, cinco apresentaram cio no dia do exame ginecológico. Este número é inferior ao que seria esperado (1/21 de $207=9,85$ ) caso todos os 207 animais estivessem ciclando (considerando-se a duração média do ciclo estral de 21 dias); porém, é próximo ao esperado, levando-se em conta apenas as fêmeas classificadas como em ALC ou com AO $(1 / 21$ de $110=5,24)$.

Tabela 1: Manifestação de cio e ocorrência de gestação dentre as classificações de atividade ovariana determinadas pela palpação retal

\begin{tabular}{lrrrr}
\hline & Total & Anestro & AO & ALC \\
\hline Número de animais & 207 & $97(46,86 \%)$ & $29(14,01 \%)$ & $81(39,13 \%)$ \\
Sem cio observado até o $45^{\circ}$ dia & $95(45,89 \%)$ & $76(78,35 \%)$ a & $7(24,14 \%)$ b & $12(14,81 \%) b$ \\
Com cio até o $45^{\circ}$ dia & $112(54,11 \%)$ & $21(21,65 \%)$ a & $22(75,86 \%)$ b & $69(85,18 \%) b$ \\
Prenhez ao final da estação & $125(60,39 \%)$ & $36(37,11 \%)$ a & $23(79,31 \%)$ b & $66(81,48 \%) b$ \\
\hline
\end{tabular}

*Os valores seguidos de letras iguais, na linha, não diferem entre si, no nível de $0,1 \%$ de probabilidade, pelo teste de $X^{2}$.

Observou-se uma diferença significativa $(p<0,001)$ no número de animais que manifestaram cio nos primeiros 45 dias da estação de monta entre aqueles classificados como em anestro e os demais grupos. O exame ginecológico antes da estação de monta mostrou-se, de maneira geral, eficiente na determinação da condição de atividade ou inatividade ovariana. Dos animais classificados em anestro,
$21(21,65 \%)$ manifestaram cio até o final do período de inseminação, sendo que parte destes animais pode ter sido incorretamente diagnosticada como em anestro, ou o tempo relativamente longo entre o exame ginecológico e o final do período de observação de cio (60 dias) pode ter sido suficiente para que animais corretamente diagnosticados em anestro reiniciassem a ALC, mesmo conside- 
rando-se a possível ocorrência de alta incidência de cios não-observados (ou silenciosos) no primeiro cio após um período de anestro (Fonseca et al., 1983; Short et al., 1990). Um período de aproximadamente dois ciclos estrais é necessário para que folículos em início de fase antral alcancem o tamanho pré-ovulatório (Britt, 1994), e folículos nesta fase poderiam estar presentes em ovários classificados como inativos (Dawson, 1975).

Sprecher et al. (1989) observaram que o diagnóstico de inatividade luteal por palpação é sujeito a mais falsos positivos (baixa especificidade) que a falsos negativos, concluindo que a palpação retal diagnostica a condição de atividade luteal melhor que a de inatividade. Ott et al. (1986) observaram uma correlação de apenas $53,8 \%$ entre a ausência de um corpo lúteo palpável e uma baixa concentração de progesterona. Resultados divergentes foram obtidos por Hussein et al. (1992), os quais observaram maior sensibilidade e especificidade na palpação de ovários inativos em animais com menos de $1 \mathrm{ng} / \mathrm{ml}$ de progesterona plasmática.

Entre os animais classificados em ALC, 12 (14,81 \%) não tiveram cio observado no período de inseminação. A ocorrência de anestro em animais classificados como em ALC pode ser devida: a) a erros na identificação do corpo lúteo, o que segundo Sprecher et al. (1989) pode estar associado à palpação de ovários de diâmetro superior a $1,5 \mathrm{~cm}$, com morfologia compatível com a presença de um corpo lúteo, em animais em anestro; b) à presença de animais com corpo lúteo persistente, não diagnosticado devido à realização de apenas um exame ginecológico, eventualmente associado a alguma anormalidade uterina não diagnosticada, pois qualquer condição, patológica ou não, que impeça a produção de prostaglandina pelo endométrio resultará na persistência do corpo lúteo (Ferreira, 1981); e c) a falhas na observação de cio. De fato, dos 69 animais que apresentaram cio nesse grupo, em seis $(8,69 \%)$ o cio só foi observado entre $\circ 22^{\circ}$ e $045^{\circ}$ dia da estação, sugerindo uma possível falha na observação de cio anterior.
Falhas na observação de cio podem contribuir significativamente para a ocorrência de suposto anestro em um rebanho bovino.

Não houve diferença $(p>0,05)$ no número de animais observados em cio durante a estação de monta, entre aqueles classificados como em ALC ou em AO (85,18 $\%$ x $75,86 \%$ ). O exame por palpação retal foi efetivo na caracterização de ovários funcionais, mesmo na ausência de um corpo lúteo palpável, o que pode estar relacionado à não-identificação de corpos lúteos inclusos, pequenos ou com pequena área de projeção à superfície do ovário, ou mesmo ao exame em fase de pró ou metaestro, no qual um corpo lúteo poderia ser identificado num segundo exame, 12 a 14 dias após (Ferreira, 1985).

Não houve diferença $(p>0,05)$ no número de animais que manifestaram cio dentro dos grupos em anestro, $\mathrm{AO}$ ou $A L C$, entre as vacas e novilhas da raça guzerá ou mestiças (Tabela 2). Constatou-se, porém, uma maior consistência entre os resultados da palpação retal e das observações de cio nas fêmeas mestiças, ou seja, um maior percentual de vacas sem cio observado dentre as classificadas como em anestro $(80,36 \%$ contra $75,61 \%$ nas guzerá), e um maior percentual de vacas com cio observado dentre as classificadas como em ALC $(89,19 \%$ contra $81,82 \%$ nas guzerá). A maior dificuldade na avaliação funcional dos ovários da fêmea zebuína pode ter contribuído para esta diferença na raça guzerá. O tamanho médio do ovário é menor e o do corpo lúteo altamente variável (Lamorde \& Kumar, 1978, apud Pathiraja et al., 1986). O percentual de acerto na caracterização da fase luteal, em fêmeas zebuínas, é significativamente reduzido em animais com corpo lúteo de pequeno diâmetro (Pathiraja et al., 1986). Por outro lado, a menor eficiência da observação de cio, nas vacas e novilhas guzerá, pode ter sido em função de os sinais de cio serem menos evidentes e presentes por um menor período de tempo nesta raça (Vale Filho et al., 1985).

Tabela 2: Manifestação de cio e ocorrência de gestação dentre as classes determinadas pela palpação retal, para os animais da raça guzerá ou mestiços (número e percentagem)

\begin{tabular}{lrrrrrl}
\hline & \multicolumn{2}{c}{ Anestro } & \multicolumn{2}{c}{ AO } & \multicolumn{2}{c}{ ALC } \\
\cline { 2 - 7 } & Guzerá & Mestiças & Guzerá & Mestiças & Guzerá & Mestiças \\
\hline Número de animais & $41(40,20)$ & $56(53,33)$ & $17(16,67)$ & $12(11,43)$ & $44(43,14)$ & $37(35,24)$ \\
Sem cio observado & $31(75,61)$ & $45(80,36)$ & $4(23,53)$ & $3(25,00)$ & $8(18,18)$ & $4(10,81)$ \\
Com cio até o 45 dia & $10(24,39)$ & $11(19,64)$ & $13(76,47)$ & $9(75,00)$ & $36(81,82)$ & $33(89,19)$ \\
Prenhez ao final da estação & $19(46,34)$ & $17(30,36)$ & $14(82,35)$ & $9(75,00)$ & $34(77,27)$ & $32(86,49)$ \\
\hline
\end{tabular}

Vários fatores estão envolvidos na taxa de gestação ao final da estação de monta (habilidade dos inseminadores, qualidade do sêmen utilizado, identificação de cio, fertilidade dos touros, sanidade do rebanho etc.), mas a pre- 
sença de ALC é um fator imprescindível para que ocorra ovulação e posterior concepção. No caso das vacas, o anestro pós-parto é o principal responsável pelo longo período de serviço e, conseqüentemente, do maior intervalo entre partos verificado na raça guzerá (Mattos \& Rosa, 1984).

A elevada percentagem de animais sem cio, observada no grupo de vacas diagnosticado como em anestro, refletiuse em menor taxa de gestação em relação aos demais grupos. O número de animais gestantes ao final da estação de monta no grupo em anestro foi superior ao número de animais com cio observado no mesmo grupo ao início da estação, indicando a possibilidade de animais terem iniciado a ALC durante a estação. Computando-se tãosomente os animais com cio observado até o $45^{\circ}$ dia da estação de monta, não se verificou diferença na taxa de gestação entre os grupos.

\section{Conclusão}

A avaliação da atividade luteal ovariana realizada duas semanas antes da estação de monta mostrou-se efetiva na determinação da condição ovariana média do rebanho, baseada no número de cios durante a estação, e, em menor grau, no número de animais prenhes ao final da estação de monta.

\section{Abstract}

Estimating reproductive condition of a beef cattle herd can be usefull in breeding season organization. Results of an ovarian examination by rectal palpation were evaluated as a reproductive estimative parameter. This study was done in a beef cattle herd, formed of guzera (bos indicus) and guzera $x$ chianina crossbred cows and heifers. The herd included cows in a range of body score condition and postpartum period. Rectal palpations were performed 15 days before breeding season. Cows and heifers were classified as in anestrous, having signs of ovarian activitie (OA), or in cyclic luteal activitie (CLA). : The number of animal showing estrus in the first 45 days of the breeding season was lower $(p<$ $0.001)$ in the anestrous group. There was no difference $(p>0.05)$ in the number of animals showing estrus between the $O A$ and the CLA groups. There was no effect $(p>0.05)$ of breed in the number of animals in estrus among classes. The number of animals with no estrous observed in the anestrous group was reflected in a lower gestation rate in this group. Characterization of the ovarian functional status by rectal palpation, in despite of eventual palpation mistakes, can be usefull in predicting herd performance in a breeding season.

Keywords: bovine; rectal palpation; breeding season.

\section{Referências bibliográficas}

BRITT, J. Here's the theory on why early breeding works. Hoard's Dairyman, v. 139, p. 599, 1994.

DAWSON, F. L. M. Accuracy of rectal palpation in the diagnosis of ovarian function in the cow. Vet. Rec., v. 96, p. 218-220, 1975.

FERREIRA, A. M. Causas de anestro em bovinos: uma revisão. Coronel Pacheco: EMBRAPA-CNPGL, 1981. 14p. (Boletim de Pesquisa, n. 3).

Guia para diagnóstico de problemas reprodutivos em fêmeas bovinas. Coronel Pacheco: EMBRAPA-CNPGL, 1985. 49 p. (Documentos, n. 20).

Efeito da amamentação e do nível nutricional na atividade ovariana de vacas mestiças leiteiras. Tese (Doutorado em Zootecnia) - Universidade Federal de Viçosa, 1990, 132 p.

FONSECA, F.A., BRITT, J.H., McDANIEL, B.T. et al. Reproductive traits of holstein and jerseys. Effects of age, milk yield and clinical abnormalities on involution of cervix and uterus, ovulation, estrous cycles, detection of estrus, conception rate and days open. J. Dairy Sci., v. 66, p. 1128-1147, 1983.

FONSECA, V. O. Redução do período de serviço em vacas de corte. In: Congresso Brasileiro de Reprodução Animal, 9., 1991, Belo Horizonte. Anais... Belo Horizonte: CBRA, 1991. v. 2, p. 1-21.

GOMES, F. P. Curso de Estatística Experimental. 11. ed. Piracicaba, Nobel, 1985. 466 p.
HUSSEIN, F. M., PACCAMONTI, D. L., EILTS, B. E. et al. Comparison of ovarian palpation, milk progesterone and plasma progesterone in the cow. Theriogenology, v. 38, p. 431-439, 1992.

MATTOS, S., ROSA, A. N. Desempenho reprodutivo de fêmeas de raças zebuínas. Inf. Agropec., n. 10, v. 112, p. 29-34, 1984.

OTT, R. S., BRETZLAFF, K. N., HIXON, J. E. Comparison of palpable corpora lutea with serum progesterone concentrations in cows. J. Am. Vet. Med. Assoc., v. 188, p. 1417-1419, 1986.

PATHIRAJA, N., OYEDIPE, E.O., VOH JR., A.A. et al. Accuracy of rectal palpation in the diagnosis of corpora lutea in zebu cows. Br. Vet. J., v. 142, p. 467-470, 1986.

SHORT, R. E., BELLOWS, R. A., STAIGMILLER, R. B. et al. Physiological mechanisms controlling anestrus and infertility in postpartum beef cattle. J. Anim. Sci., v. 68, p. 799-816, 1990.

SPRECHER, D. J., NEBEL, R. L., WHITMAN, S. S. The predictive value, sensitivity and specificity of palpation per rectum and transrectal ultrasonography for the determination of bovine luteal status. Theriogenology, v. 31, p. 1165-1172, 1989.

VALE FILHO, V. R., PINHEIRO, L. E. L., BASRUR, P. K. Reproduction in Zebu Cattle. In: Current Therapy in Theriogenology, Saunders, Philadelphia: Saunders. p. 437442, 1985. 